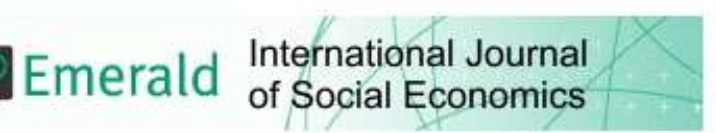

\title{
Socioeconomic inequalities in child obesity and overweight in Portugal
}

\begin{tabular}{|r|l|}
\hline Journal: & International Journal of Social Economics \\
\hline Manuscript ID & IJSE-11-2015-0291.R2 \\
\hline Manuscript Type: & Research Paper \\
\hline Keywords: & $\begin{array}{l}\text { child obesity and overweight, health inequalities, socioeconomic status, risk } \\
\text { factors, concentration index, Portugal }\end{array}$ \\
\hline \multicolumn{2}{l}{} \\
\hline
\end{tabular}

\section{SCHOLARONE ${ }^{\mathrm{W}}$ \\ Manuscripts}


Title: Socioeconomic inequalities in child obesity and overweight in Portugal

\begin{abstract}
Purpose: To assess the association between socioeconomic status and child overweight/obesity in Portugal and to evaluate income related inequalities in its distribution.
\end{abstract}

Design/methodology/approach: Data come from the last Portuguese National Health Survey (2005/2006) - sample of 6903 observations. To define child overweight/obesity, the International Obesity Task Force cut-offs for BMI were used; the logistic regression analysis was adopted to explain the risk of overweight/obesity and inequality was measured by means of concentration curve and index.

Findings: The evidence obtained points to income-related inequalities in child overweight/obesity favourable to the better-off. The probability of child overweight/obesity was lower for higher income households, but up to a certain point a positive association between income and caloric food intake was found. The concentration index obtained was -0.072 ( $p$-value $<0.001)$.

Research limitations/implications: Some data limitations (no information on: physical exercise; sleeping habits; parents' education and BMI; age is coded in groups). Although the data is from 2005/2006 the current analysis is useful to future works aiming to discuss the impact of the economic and financial crisis which occurred after this data was collected.

Social implications: It is important to tailor policies targeting child obesity/overweight in order to tackle not only the prevalence of this disease but also its distribution.

Originality/value: Drawing attention on inequalities in child obesity/overweight in Portugal as the vast majority of studies have focused on prevalence. The middle income effect is an issue pointed in this work which deserves further investigation.

Keywords: child obesity and overweight, health inequalities, socioeconomic status, risk factors, concentration index, Portugal. 


\section{Introduction}

In a wide range of countries (now including middle- and low-income countries), high and increasing rates of overweight and obesity have been reported in children and adolescents over recent decades (Waters et al., 2011; Costa-Font and Gil, 2013). This is a worrying situation given the link established between child obesity and many serious physical, social and psychological consequences such as risk of cardiovascular disease, type 2 diabetes, hepatic, renal and musculoskeletal disorders, lower health-related quality of life and negative emotional states complications, both at younger ages and later in life (Waters et al., 2011).

Although child obesity affects all social classes, countries and cultures, the burden of this disease is not evenly distributed (Freudenberg, 2013). Thus, the situation among children is similar to what happens with adult obesity and overweight which tend to be more prevalent in disadvantaged socioeconomic groups with these inequalities virtually stable during the last 15-20 years (Devaux and Sassi, 2013; Hajizadeh, Campbell and Sarma, 2014). Indeed, socioeconomic status (SES) is often found to be inversely associated with child obesity and, unlike in adults, obesity in children is strongly influenced by parental choice of lifestyles and the child's overall social environment, in addition to genetic transmission (Costa-Font and Gil, 2013). The focus on, and efforts to reduce, child obesity have not been followed by actions to reduce the wide and growing inequalities in this area. Public policy discussions about obesity usually fail to distinguish between drivers of obesity and drivers of inequalities in obesity (Freudenberg, 2013). The differential distribution of three resources (food, physical activity opportunities and health care) has been identified as main drivers of inequalities in child obesity (Freudenberg, 2013; Kulpers, 2012). A fourth driver of inequality is suggested by Wilkinson and Pickett (2009) who argue that the social stressors associated with the social gradient and income inequality can influence all other pathways including sedentarism, caloric intake, food choice and the physiological effects of stress. Failing to address and tackle inequalities in child overweight and obesity will help to perpetuate global inequalities in health.

In Portugal, overweight and obesity among children and adolescents is an important public health problem and various studies have sought to assess its prevalence. The 
precise figures differ between studies but in all cases, and irrespective of the cut-offs used to categorise overweight and obesity, results point to high prevalence of these phenomena (Sardinha et al., 2011; Antunes and Moreira, 2011; Albuquerque et al., 2011). A review of the literature (Antunes and Moreira, 2011), covering 21 empirical studies for Portugal, found percentages of child overweight between $8.3 \%$ and $29.6 \%$ for boys and between $8.8 \%$ and $35 \%$ for girls. Regarding obesity, the rates varied between $3.2 \%$ and $26 \%$ for boys and between $0.6 \%$ and $21.3 \%$ for girls. According to the latest evidence from OECD, Portugal comes eighth in a list of 40 countries, with a prevalence of child overweight and obesity close to 30 per cent (OECD, 2013).

Following the worldwide tendency of paying less attention to inequalities in child overweight and obesity (Waters et al., 2011), most studies in Portugal have focused on prevalence (Freudenberg, 2013). Still, the limited evidence shows inequalities in favour of the better-off. A negative association between obesity and socioeconomic status (assessed by parental education) has been found, while a positive association emerged for the case of sports activity. Additionally, parents of children with the lowest SES were less likely to have positive perceptions of their built environment (Nogueira et al., 2013a, 2013b). There is also evidence that lower SES children tend to have lower levels of interest in physical activity, lower perceived physical competence and less parental support for physical activity. This puts them at greater risk of being physically inactive (Seabra et al., 2103). In this last study, the uptake of subsidised school education material and meal programmes by families was used as a proxy for SES.

It thus seems that in Portugal not only is the prevalence of child overweight and obesity high but that there are inequalities too. However, the evidence for inequalities is much scarcer than that for prevalence. Moreover, most studies did not use representative samples (Antunes and Moreira, 2011). Hence, the aim of this study is to provide evidence on inequalities using data from the latest National Health Survey. Specifically, the main objectives are to assess the association between socioeconomic status and child overweight/obesity and to assess the existence of income related inequalities in its distribution, in the context prior to the economic and financial crisis that hit the country. 


\section{Material and methods}

Data came from the fourth and latest National Health Survey, applied jointly by National Health Institute (INSA) and Statistics Portugal (INE), from February 2005 to February 2006. The final database includes information on 15457 households, covering residents in the mainland and the archipelagos of Azores and Madeira (INSA and INE, 2009).

For the current study, only data for children and adolescents up to 18 years old were relevant. However, the information on age was grouped into the following bands in the database: $0 ; 1-4 ; 5$ - 9; 10 - $14 ; 15$ - 19; 20 - 24; 25 - 29;30 - 34; 35 - 39; 40 $44 ; 45$ - 49; 50 - 54; 55 - 59; 60 - 64; 65 - 69; 70 - 74; 75 - 79; 80 - 84; 85+. Therefore, the analysis was carried out using age bands and not the precise age of children as this information is not available; additionally, those aged 19 had to be included in the analysis. On the other hand, due to lack of relevant information (weight and height), children up to 4 years old were excluded. Thus, the final sample was composed of 6903 observations, including children and adolescents aged 5 to 19. Sampling weights used in the fourth Portuguese National Health Survey are not straightforward (INSA and INE, 2009, pp.29-31), thus, we did not include these weights in the analysis, following the procedure adopted in other studies using the same database, e.g., Furtado and Pereira (2010) and Ribeiro (2010). This might however have implications to the generalisation of the findings as acknowledged in the discussion section.

Overweight and obese children/adolescents are those whose body mass index (BMI) is above a set of age- and sex-specific cut-off points. The International Obesity Task Force (IOTF) BMI cut-offs (Cole et al., 2000), which have been adopted as a reference for measuring overweight and obesity in other studies and countries, were also used in the current work. In any case, given that the concerns here are not focused on prevalence values per se, the thresholds used are not crucial for the results. Obesity and overweight rates rely on individual height and weight data which can either be measured by examination or self-reported. In the National Health Survey, information regarding weight and height were reported by parents, or in the case of adolescents aged 15 or over, data were self-reported. Self-reported data tend to underestimate 
overweight and obesity (Sardinha et al., 2011; OECD, 2013), but again this should not affect the main results since what matters most in this study is the distribution and not absolute values (still this issue is discussed below). For each age band the average cutoff points from IOTF were used. Overweight and obesity were analysed together as in e.g. OECD (2013). The (binary) dependent variable took the value 1 if the child/adolescent was overweight or obese and zero otherwise.

Multiple logistic regression analysis was used to evaluate the association between risk factors and overweight/obesity. As covariates all relevant information available in the database was included (all variables were drawn from the same source - the fourth National Health Survey). As explained previously children under 5 years old had to be excluded and it was not possible to exclude those aged 19. Thus, three age bands were considered: $5-9 ; 10-14 ; 15-19$. The variable sex was also included. Information on age and sex came from section 1 of the database. Information on residence was grouped in the database by NUTs II regions; hence, this variable had to be grouped according to NUTs II (seven regions). As a proxy for socioeconomic status the monthly family income was used, a variable that came from section 10 of the database. Again the information was grouped in ten income groups in the database (consequently income was considered as a categorical variable). Regarding lifestyles it was not possible to consider physical exercise because there was no information on children/adolescents under 15 with respect to this variable. Still, section 12 of the database (about lifestyles) provided some information on food intake. More specifically, it indicated whether the child/adolescent did or did not consume certain types of food at main meals on the day prior to the interview (the list included milk, soup, bread, meat, fish, potatoes/rice/pasta, beans, salad/vegetables) and whether the child/adolescent did or did not consume certain types of food between meals on the day prior to the interview (the list included bread, yogurt, juice, soft drinks, cakes/chocolates/sweet desserts, candies, chips). Based on the information available, consuming soup or salad/vegetables at main meals were used as proxies for healthy lifestyles, while consuming soft drinks or cakes/chocolates/sweet desserts or chips or candies between meals were used as proxies for unhealthy lifestyles. It would not be very informative to consider all food types, as all children and adolescents were expected to have consumed at least some of the items presented. Plus, no information was available on 
quantities therefore items whose impact on health depends on the quantity consumed were avoided (e.g. eating pasta might be good for children's health but eating too much of it might be harmful to health).

To estimate the income related inequalities in child overweight/obesity the traditional procedures based on concentration curves and on the calculation of concentration indices were followed (O'Donnell et al., 2008). The concentration curve plots the cumulative percentage of the health variable ( $y$-axis) against the cumulative percentage of the population, ranked by living standards, beginning with the poorest and ending with the richest (x-axis). In this study, the health variable of interest is child overweight/obesity and living standards are measured by family income. In the absence of inequality, the concentration curve coincides with the diagonal (line of equality); if the concentration curve lies above (below) the diagonal then the health variable (in this case, child overweight/obesity) is concentrated among the worse-off (better-off). The concentration index is directly related to the concentration curve and quantifies the degree of socioeconomic related inequality in the health variable (O'Donnell et al., 2008). The concentration index is defined as twice the area between the concentration curve and the line of equality. Where there is no socioeconomic related inequality, the concentration index is zero. The convention is that the index takes a negative value when the curve lies above the line of equality, indicating disproportionate concentration of the health variable among the poor, and a positive value when it lies below the line of equality. In this study, the concentration index was calculated using the convenient regression approach (Kakwani et al., 1997; O'Donnell et al., 2008). It has been demonstrated that when the concentration index is used to measure income-related inequality in a binary variable (as it is the case in the current study), its bounds do not extend to -1 and +1 , but rather are equal to $\mu-1$ and $1-\mu$, where $\mu$ is the mean of the variable being analysed (Wagstaff, 2005, 2011). Therefore, we present the results for the normalised index suggested by Wagstaff $(2005,2011)$ : if $C$ is the standard concentration index, the normalised concentration index is equal to $C /(1-\mu)$. For an alternative corrected version of the concentration index see Erreygers (2009).

SPSS for Windows (version 21.0) was used to analyse the data. A p-value of 0.05 denoted statistical significance. 
25

26

27
28

29

30

31

33

34

35

36

37

38

40

41

42

43

44

45

46

47

48

49

51

52

53

54

55

57

58

60 


\section{Results}

Table 1 defines the variables and shows the composition of the sample. About half of the sample corresponds to boys and the observations are evenly distributed over all three age bands as well as across regions; $50 \%$ of children and adolescents belong to families whose monthly income was between 501 Euros and 1200 Euros while in 15\% of cases families reported a monthly income up to 500 Euros. A large majority of children/adolescents (84\%) consumed soup and/or salad on the day prior to the interview and a fifth consumed soft drinks and/or chips. A significant proportion (37\%) consumed sweets.

\section{Insert Table 1 about here}

Table 2 shows a high prevalence of overweight and obesity (27.9\%) among Portuguese children and adolescents, as found in this study. This result falls in the range identified in other studies (Antunes and Moreira, 2011). Thus, the evidence generated by the fourth National Health Survey is in line with other sources (but note that comparisons of studies are not straightforward; the current results for prevalence are comparable only with results obtained from studies using the same cut-offs and ages). Prevalence is higher for boys and for younger children. In terms of regions of residence, the Azores emerges as the region with the highest percentage of overweight and obese children and adolescents while Alentejo has the lowest percentage. In most regions, the prevalence is higher among boys than among girls (though in Madeira and the North the difference between sexes was small - lower than $1 \%)$.

Insert Table 2 about here

Focusing now on the prevalence by income groups (Figure 1), it can be observed that overall overweight/obesity decreases as income increases though in the middle income group (800 Euros -1050 Euros) there is a slight increase and in the highest income group (2000 Euros or higher) the prevalence among boys does not diminish as it happens with girls.

Insert Figure 1 about here

Looking at food intake by income groups (Figure 2) there are two types of healthy food (soup and salad) and three unhealthy foods/drinks (soft drinks, sweets and chips). In 
the highest income group the percentage of children and adolescents who consumed healthy food is greater than in all other income groups, even for soup, which is not an expensive item. The intake of soft drinks and chips increases with income up to the middle income group but then it decreases. There seems to be two distinct effects of income. These results will be discussed further in the next section. For the case of sweets (cakes, chocolates and candies), again the consumption increases up to the middle income group then it decreases but goes up again in the highest income group.

Insert Figure 2 about here

Table 3 shows the association between different characteristics and overweight/obesity (we took as reference categories the last group for each variable). As expected from the exploratory analysis, boys are 1.2 times more likely to be overweight/obese than girls, and this effect is statistically significant. Regarding age, the risk is greater for younger ages. Specifically, children aged 5 to 9 are 3.7 times more likely to be overweight/obese than adolescents aged 15 to 19; children/adolescents aged 10 to 14 also face a greater risk than adolescents aged 15 to $19(\mathrm{OR}=1.6)$ but not as high as the 5-9 group. In both cases the effects are statistically significant. In terms of regions of residence, in all regions except for Azores the risk of overweight/obesity is lower compared to Madeira (this too is in line with results in Table 2). Still, the effects are statistically significant only for Lisbon and Alentejo, where the risk of overweight/obesity decreases about $20 \%$ and $30 \%$, respectively. In terms of income, the results in Table 3 show values for the odds ratio greater than 1 for all income groups (compared to income greater than 2000 Euros), suggesting that the risk of overweight/obesity in children and adolescents is lower in the highest income group than in all the other groups. For income groups between 250 and 1200 Euros, the odds ratios vary between 1.3 and 1.5 and are statistically significant. For the two lowest income groups, the odds ratios are actually higher but in both cases they are statistically significant only at the $10 \%$ level ( $p$-value < 0.1 ) - note that the sample includes a small proportion of families with incomes as low as this (Table 1). For income groups between 1200 and 2000 Euros the odds ratios are greater than 1 but lower than in the other groups and they are not statistically significant. Again there seems to be a middle income effect. Finally, two unexpected effects for food intake were obtained. First, an odds ratio greater than 1 was obtained for the consumption of 
healthy food, though it is not statistically significant. An odds ratio lower than 1 was found for the consumption of sweets, though only statistically significant at the $10 \%$ level. As seen earlier (Figure 2), there was no clear tendency in the consumption of sweets, thus, the results should reflect mixed effects. The impact of fats and/or soft drinks, on the other hand, was as anticipated. Children and adolescents who consume this type of unhealthy food are 1.3 times more likely to be overweight/obese (statistically significant).

\section{Insert Table 3 about here}

The analysis of the distribution of child overweight/obesity suggests that there are income related inequalities because the concentration curve for this variable differs from the line of equality (Figure 3). Moreover, given that the concentration curve lies above the diagonal, it indicates a disproportionate concentration of this disease among the poorer families. Nonetheless, for the first income quartile the concentration the curve almost overlaps the diagonal. It is from this point on that it departs from the line of equality. The normalised concentration index obtained is -0.072 (statistically significant; $p$-value $<0.001)$. This calculation confirms the existence of inequalities (index different from zero) and the negative value suggests the concentration of the disease among the worse-off.

Insert Figure 3 about here 


\section{Discussion}

In this study, using the fourth National Health Survey for the first time to evaluate overweight and obesity among children and adolescents in Portugal, it was found a high rate of prevalence of overweight/obesity which agrees with other findings. The main focus, however, was on socioeconomic inequalities in this disease. Based on the results, the conclusion is that the risk of child overweight/obesity is greater in families with lower incomes. Nonetheless, a middle income effect was also obtained. That is, the impact of income is statistically significant only in the middle income groups and the analysis of dietary habits also shows that up to a certain point unhealthy food intake and income are positively associated, after which, for the highest income groups the association becomes negative. Although it is recognised that higher income enables access to healthier food and more opportunities for physical activities (Freudenberg, 2013), it seems that in the middle of the income distribution more income might produce some harmful consequences as it improves access to caloric items such as chips and soft drinks. For the highest income groups, it might be that, despite the access to caloric items, other factors identified in the literature (parents' knowledge and skills, particularly the ability to choose and plan meals and occupy free time) protect children from obesity. The percentage of children and adolescents who consumed soup, for example, is higher among the richest, which is not explained by greater purchasing power. In fact, these opposite effects of income have been observed in cross-country analyses as well. That is, in developed countries a significant trend between obesity and lower socioeconomic status has been observed, while in some developing countries the opposite is found, with children from relatively affluent families seemingly more vulnerable to obesity (Waters et al., 2011). For the case of adults, Hajizadeh, Campbell and Sarma (2014) also found a consistent inverse relationship between income and obesity risk among women, but for men their results indicated that obesity is concentrated among the better off individuals, especially in recent years. In the same line, Villar and Quintana-Domeque (2009) investigated the relationship between household income and body mass index (BMI) in nine European countries obtaining an inverse relationship in women and mixed patterns for men, but in Portugal they actually found higher BMI in men from higher income groups. Finally, King et al. (2015) concluded that in low-income countries, obesity was more prevalent 
in individuals with higher education, while in medium-income and high-income countries obesity shifts to be more prevalent among those with lower levels of education.

Following the suggestion from an anonymous reviewer, to investigate the association between risk factors and child overweight/obesity, we further explored the data using a different regression model, specifically, we used the generalized linear model with a probit link function. We obtained negative and statistically significant coefficients for age, sex (female), income, salad and soft drinks. Positive coefficients were obtained for cakes, chips and sweets but only significant in the latter case. These results generally corroborate the findings reported in Table 3, suggesting lower risk in older children, girls, and higher income families and here too the effects regarding lifestyles were less clear-cut.

The concentration curve and index calculated in this study also confirms that there are inequalities in the distribution of child overweight/obesity and that this disease is concentrated among the worse-off. The magnitude of the inequality obtained in the current study $(-0.072)$ is similar to the inequality in obesity among adults aged 35 to 74 - concentration index of -0.077 (normalised), based on the fourth National Health Survey as well (Ribeiro, 2010). The extent of inequalities does not seem to change much between adults and children though these comparisons are only approximations due to data limitations, plus, our concentration index is calculated jointly for obesity and overweight. Walsh and Cullinan (2015), for example, using data from 2007 and 2008 (fairly from the same period as the data used in our study), analysed childhood obesity and overweight in Ireland and obtained a social gradient more pronounced for obesity $(\mathrm{Cl}=-0.168)$ than for obesity/overweight $(\mathrm{Cl}=-0.057)$. This means that our results might conceal deeper inequalities in child obesity.

Child overweight and obesity is a public health problem worldwide but policy interventions should pay attention to inequalities and not focus on total prevalence alone. It has been acknowledged that many national and municipal governments are taking action to address the main drivers of elevated BMIs but few are acting aggressively to change the distribution. The result of such policies could be that the better-off benefit more from interventions than the poor, thus actually widening the 
gap (Waters et al., 2011). The World Health Organisation has warned that socioeconomic inequities in obesity in Europe are widening and the gradient is becoming steeper; unless equity is explicitly taken into consideration, the business-asusual approach tends to create policies, programmes and services that have a social gradient in their effect (Loring and Robertson, 2014).

To reduce inequalities, the drivers of inequality must be evaluated and different options must be balanced. Interventions might be upstream (e.g. reducing income inequality, poverty and social marginalisation) or downstream (enhancing access of atrisk populations to services and programmes designed to reduce obesity at the individual level); interventions might be universal or targeted (e.g. free meals for all students versus meals only for students from deprived families); a balance must also be made between regulation and education (e.g. campaigns to educate parents about the benefits of healthy food versus banning the promotion of obesogenic foods to children) as well as between works at the local versus the regional or national levels (Freudenberg, 2013). But it is crucial to evaluate the impact on different social groups to avoid unintended consequences for inequities. For instance, where information strategies are used, specific effort is needed to ensure the messages are designed with and for the most disadvantaged groups (e.g. consumers with low numeracy or literacy skills may be more receptive to pictograms/pictures or traffic-light labelling, compared with detailed numerical nutritional information on food labels) (Loring and Robertson, 2014).

In Portugal, the increasing rates of prevalence of overweight and obesity have led to greater importance being attributed to this health problem in strategic health plans, though it is suggested that concerns over child overweight and obesity have been reflected in these plans only quite recently (Beja et al., 2014). Some efforts have also been registered at local level (Loureiro and Freudenberg, 2012). Still, with few exceptions (Rito et al., 2013), the main focus continues to be on total prevalence and inequalities have been largely ignored. Given the rising rates of diet-related noncommunicable diseases, failing to take action to reduce inequalities in child overweight and obesity might jeopardise the achievement of global goals of health equality. 
Some limitations apply to the current study, mostly due to data limitations. The database does not allow matching between children and their parents. Hence, it was not possible to consider an important SES variable which is parental education. There is some evidence that points to pro-rich socioeconomic inequalities being intermediated by parental education (Costa-Font and Gil, 2013) influences as well as mother's employment (Anderson at al., 2003), but it was not possible to include these variables in the analysis because this information was not in the database. Also, there is no information on physical exercise for children/adolescents less than 15 years old nor on weight and height for children under 5 years old; information on hours of sleep was not collected.

For each child, the database provides information only on the age band to which the child belongs, implying that average cut-off points had to be used. Consequently, in each age band it might occur an underestimation (overestimation) of overweight and obesity of younger (older) children. However, assuming that the biases apply to all socioeconomic groups then this limitation should not represent a problem for the inequality analysis.

Another limitation of the database is that it does not provide information on the number of members in each household, meaning that it is not possible to calculate equivalent income. But in terms of ranking children, using total income or equivalent income should not produce very different results given the income disparities observed in Portugal (irrespective of family size, members from poorer households are expected to rank low in the equivalent income distribution and members from richer households are expected to rank high).

The authors of the current study insisted and contacted Statistics Portugal to try to overcome these data limitations but were told that it was not possible to get such information. In future waves of the National Health Survey it is highly recommended to collect/make available these types of information as they are crucial to carry out different analyses, namely to analyse children's health.

Another potential limitation of the analysis stems from the fact (already mentioned in the methods section) that self-reported data tend to underestimate overweight and obesity. This could have implications to the main results obtained in this study 
(inequalities) if misreporting varied with socioeconomic status. Indeed, it has been suggested that, for the case of adults, misreporting may matter for estimated educational and income disparities in BMI and obesity (Ljungvall et al., 2015). Bu if these findings also hold for the sample used in the current study the implication is that the results presented here actually underestimate socioeconomic disparities and the problem is even more serious.

The proxies used for eating habits might also not accurately reflect and fully capture what children do in their daily life. Still, these variables are included in the National Health Survey to capture life styles and in the analysis using groups of individuals (classified by income) the expectation is that average values are close to the norm.

Because sampling weights were not used (as explained in the method section), the findings can be confidently generalised only to the children in our sample. Still, regarding the concentration index, O'Donnell et al. (2008, p.103) say that standard errors from the convenient regression equation can be used without too much concern for inaccuracy.

Finally, the data used in this study are nearly ten years old, which might be regarded as a limitation. However, it presents the advantage of being a large sample of Portuguese children (not previously used to analyse child obesity and overweight) and the results obtained in this study might also be useful for future comparisons, to evaluate the impact of the recent economic crisis on inequalities.

In the case of adults, evidence shows that regardless of their income or wealth, people who experience periods of financial hardship are at increased risk of obesity (OECD, 2014a). Evidence has further shown that across the OECD area, children and young people were hardest hit by income poverty (OECD, 2014b). For the particular case of Portugal, between 2012 and 2013, the country had the largest rate of increase in the at-risk-of-poverty or social exclusion rate in the EU-28 and since the implementation of major cuts, Portugal has reduced by 30 per cent its spending on support for families with children and one-third of beneficiaries have lost access to child benefits (Caritas Europa, 2015); the rate of increase in child poverty was also marked between 2012 and 2013 (Caritas Europa, 2015). According to OECD (2014b), social transfers (unemployment, social assistance, disability and family benefits) have been the focus 
of by far the greatest number of consolidation measures since 2011. The impact of the crisis on child obesity and overweight is not known but a recent report for Portugal points to worrying indicators with child obesity rising fast: obesity amongst children in Portugal is higher than the OECD average, for both boys and girls, and children in Portugal do less daily moderate-to-vigorous activity than children in most other OECD countries (OECD, 2015).

The report (OECD, 2015) also underlines the need to develop guidance around how primary care practitioners can help with the prevention of overweight and obesity. This is an important channel to carry out prevention measures as access to primary care services is widespread across de country. But guidelines should not overlook the dimension of inequalities. Discussions on the impact of the crisis on child obesity continue to focus on prevalence. The effects of the crisis on inequalities might not be straightforward. Financial constraints might lead more people to use public transports, to prepare homemade meals (instead of eating out) and to cut on food items such as sweets but, on the other hand, some people might substitute healthier food by fast food (when this implies lower spending) and cuts regarding sport activities might also occur. Therefore, there is the need to monitor the evolution of inequalities and whether the crisis has widened or narrowed them.

\section{Conclusion}

Using a large sample of Portuguese children, a high prevalence of child overweight and obesity was obtained, but above all, the results agree with the literature in pointing to a negative association between income and the risk of child overweight and obesity and suggesting that there are income related inequalities in the distribution of this disease. A middle income effect was also found, that is, the increased risk of obesity was statistically significant only in the middle of the income distribution. The results further show opposite impacts of income; up to a certain point income is positively associated with caloric food intake while in the highest income groups this association is reversed which probably reflects the impact of other variables like parental education. These findings deserve further investigation, particularly the hypothesis that in the extremes of the income distribution some healthy life styles are more likely 
to emerge (though for different reasons - in one case, due to financial constraints and

in 2 he other case due to rational and informed decisions) and it is in the middle of the income distribution that more serious problems arise. For now, child overweight/obesity is recognised as an important public health problem but the main focus of research and strategic health plans, in Portugal as well as in other countries, has been on the prevalence. Greater attention must be paid to inequalities, too, otherwise existing gaps might continue to grow and the most fundamental goals of health equity and equality will move farther from our reach.

\section{Acknowledgments}

We thank two anonymous reviewers of this journal for their thoughtful comments and suggestions which have improved the manuscript.

\section{References}

Albuquerque, D., Nóbrega, C., Samouda, H. et al., (2012), “Assessment of obesity and abdominal obesity among Portuguese children", Acta Médica Portuguesa, Vol. 25, pp. 169-173.

Anderson, P.M., Butcher, K.F. and Levine, P. (2003), "Maternal employment and overweight children", Journal of Health Economics, Vol.22, pp. 477-504.

Antunes, A. and Moreira, P. (2011), "Prevalence of overweight and obesity among Portuguese children and adolescents" (Portuguese), Acta Médica Portuguesa, Vol. 24, pp. 279-84.

Beja, A., Ferrinho, P. and Craveiro, I. (2014), "Evolution of prevention of obesity in children and adolescents in Portugal at the level of strategic planning" (Portuguese), Revista Portuguesa de Saúde Pública, Vol. 32, pp. 10-17.

Caritas Europa (2015), Poverty and inequalities on the rise, Caritas Europa, Brussels.

Cole, T.J., Bellizzi, M.C., Flegal, K.M. et al. (2000), “Establishing a standard definition for child overweight and obesity worldwide: international survey", British Medical Journal, Vol. 320, pp. $1240-1243$. 
Costa-Font, J. and Gil, J. (2013), "Intergenerational and socioeconomic gradients of child obesity", Social Science \& Medicine, Vol. 93, pp. 29-37.

Devaux, M., Sassi, F. (2013), "Social inequalities in obesity and overweight in 11 OECD countries", European Journal of Public Health, Vol. 23, pp. 464-469.

Erreygers, G. (2009), "Correcting the concentration index", Journal of Health Economics, Vol. 28, pp. 504-515.

Furtado, C. and Pereira, J. (2010), Equity and access to health care (Portuguese), Alto Comissariado da Saúde, Lisboa.

Freudenberg, N. (2013), “Commentary: Reducing inequalities in child obesity in developed nations: What do we know? What can we do?", Revista Portuguesa de Saúde Pública, Vol. 31, pp.115-122.

Villar, J.G. and Quintana-Domeque, C. (2009) "Income and body mass index in Europe", Economics and Human Biology, Vol.7, pp.73-83.

Hajizadeh, M., Campbell, K., Sarma, S. (2014), "Socioeconomic inequalities in adult obesity risk in Canada: trends and decomposition analyses", European Journal of Health Economics, Vol. 15, pp. 203-221.

INSA and INE (2009), “National Health Survey 2005/2006” (Portuguese), available at: http://www.insa.pt/sites/INSA/Portugues/Publicacoes/Outros/Documents/Epidemiolo gia/INS_05_06.pdf (accessed 2 November 2015).

Kakwani, N.C., Wagstaff, A. and van Doorslaer, E. (1997), "Socioeconomic inequalities in health: measurement, computation and statistical inference", Journal of Econometrics, Vol. 77, pp. 87-104.

Kulpers, Y.M. (2012), "Focusing on obesity through a health equity lens", Obesity Review, Vol. 13, Suppl. 1, pp. 29-41.

King, J.M., Strand, B.H., Vollset, S.E., Skirbekk, V. (2015), "Educational inequalities in obesity and gross domestic product: evidence from 70 countries", Journal of Epidemiology and Community Health, Vol. 69, pp. 1141-1146. 
Loring, B. and Robertson, A. (2014), "Obesity and inequities: Guidance for addressing inequities in overweight and obesity", WHO Regional Office for Europe, Copenhagen.

Loureiro, M.I. and Freudenberg, N. (2012), "Engaging municipalities in community capacity building for childhood obesity control in urban settings", Family Practice, Vol. 29, Suppl 1, pp.i24-i30.

Ljungvall, A., Gerdtham, U. G. and Lindblad, U. (2015), “Misreporting and misclassification: implications for socioeconomic disparities in body-mass index and obesity", European Journal of Health Economics, Vol. 16, pp. 5-20.

Nogueira, H., Gama, A., Mourão, I. et al. (2013a), “The associations of SES, obesity, sport activity, and perceived neighborhood environments: Is there a model of environmental injustice penalizing Portuguese children?", American Journal of Human Biology, Vol. 25, pp. 434-436.

Nogueira, H., Ferrão, M., Gama, A. et al. (2013b), “Perceptions of neighborhood environments and childhood obesity: Evidence of harmful gender inequities among Portuguese children", Health \& Place, Vol. 19, pp. 69-73.

O’Donnell, O., van Doorslaer, E., Wagstaff, A. et al. (2008), Analyzing Health Equity Using Survey Data: a guide to techniques and their implementation. The World Bank, Washington D.C..

OECD (2013), Health at a Glance 2013: OECD Indicators, OECD Publishing, Paris.

OECD (2014a), Health at a Glance 2014: OECD Indicators, OECD Publishing, Paris.

OECD (2014b), Society at a Glance 2014: OECD Social Indicators, OECD Publishing, Paris.

OECD (2015), OECD Reviews of Health Care Quality: Portugal 2015: Raising Standards, OECD Publishing, Paris.

Ribeiro, S. (2010), Socioeconomic inequalities in cardiovascular disease in Portugal - a study based on the 4th National Health Survey (Portuguese), Master Dissertation in Health Management, Escola Nacional de Saúde Pública, Lisboa. 
Rito, A., Carvalho, M., Ramos, C. and Breda J. (2013), "Program obesity zero (POZ) - a community based intervention to address overweight primary-school children from five Portuguese municipalities", Public Health Nutrition, Vol. 16, pp. 1043-1051.

Sardinha, L.B., Santos, R., Vale, S. et al. (2011), "Prevalence of overweight and obesity among Portuguese youth: A study in a representative sample of 10-18-year-old children and adolescents", International Journal of Pediatric Obesity, Vol. 6. pp. e124e128.

Seabra, A., Mendonça, D., Maia, J. et al. (2013), "Gender, weight status and socioeconomic differences in psychosocial correlates of physical activity in schoolchildren", Journal of Science and Medicine in Sport, Vol. 16, pp. 320-326.

Waters, E., de Silva-Sanigorski A., Hall, B.J., et al. (2011), "Interventions for preventing obesity in children", Cochrane Database Systematic Reviews, Vol. 12.

Wagstaff, A. (2005), "The bounds of the concentration index when the variable of interest is binary, with an application to immunization inequality". Health Economics, Vol. 14, pp. 429-432.

Wagstaff, A. (2011), "Health economics letter: The concentration index of a binary outcome revisited", Health Economics, Vol. 20, pp. 1155-1160.

Walsh, B. and Cullinan, J. (2015), "Decomposing socioeconomic inequalities in childhood obesity: Evidence from Ireland", Economics and Human Biology, Vol. 16, pp. $60-72$.

Wilkinson, R. and Pickett, K. (2009), The spirit level: why more equal societies almost always do better, Allan Lane, London. 


\begin{tabular}{|c|c|c|}
\hline Variables/characteristics & Definition & Mean \\
\hline \multicolumn{3}{|l|}{ Sex: } \\
\hline Male & $=1$ if male & 0.52 \\
\hline \multicolumn{3}{|l|}{ Age (years): } \\
\hline $5-9$ & $=1$ if aged between 5 and 9 & 0.31 \\
\hline $10-14$ & $=1$ if aged between 10 and 14 & 0.32 \\
\hline $15-19$ & $=1$ if aged between 15 and 19 & 0.37 \\
\hline \multicolumn{3}{|l|}{ Residence: } \\
\hline North & $=1$ if lives in North & 0.15 \\
\hline Centre & $=1$ if lives in Centre & 0.12 \\
\hline Lisbon & $=1$ if lives in Lisbon and Tagus Valley & 0.13 \\
\hline Alentejo & $=1$ if lives in Alentejo & 0.12 \\
\hline Algarve & $=1$ if lives in Algarve & 0.12 \\
\hline Azores & $=1$ if lives in Azores & 0.20 \\
\hline Madeira & $=1$ if lives in Madeira & 0.16 \\
\hline \multicolumn{3}{|l|}{ Income: } \\
\hline$\leq 150$ & $=1$ if monthly family income is $€ 150$ or lower & 0.007 \\
\hline $151-250$ & $=1$ if monthly family income is between $151 €$ and $250 €$ & 0.016 \\
\hline $251-350$ & $=1$ if monthly family income is between $251 €$ and $350 €$ & 0.032 \\
\hline $351-500$ & $=1$ if monthly family income is between $351 €$ and $500 €$ & 0.097 \\
\hline $501-700$ & $=1$ if monthly family income is between $501 €$ and $700 €$ & 0.15 \\
\hline $701-900$ & $=1$ if monthly family income is between $701 €$ and $900 €$ & 0.17 \\
\hline $901-1200$ & $=1$ if monthly family income is between $901 €$ and $1200 €$ & 0.20 \\
\hline $1201-1500$ & $=1$ if monthly family income is between $1201 €$ and $1500 €$ & 0.13 \\
\hline $1501-2000$ & $=1$ if monthly family income is between $1501 €$ and $2000 €$ & 0.078 \\
\hline$>2000$ & $=1$ if monthly family income is greater than $2000 €$ & 0.12 \\
\hline
\end{tabular}




$\begin{array}{lll}\text { Healthy food } & =1 \text { if child consumed soup and/or salad } & 0.84 \\ \text { Unhealthy-sweets } & =1 \text { if child consumed cakes/chocolates and/or other sweets } & 0.37 \\ \text { Unhealthy-drinks/chips } & =1 \text { if child consumed soft drinks and/or chips } & 0.21\end{array}$


Table 2 - Prevalence of overweight/obesity by sex, age and region, in Portuguese children and adolescents aged 5 to 19 , according to the International Obesity Task Force cut-offs of BMI

\begin{tabular}{|c|c|c|c|}
\hline Characteristics & Boys (\%) & Girls (\%) & Total (\%) \\
\hline Total & 29.8 & 25.9 & 27.9 \\
\hline \multicolumn{4}{|l|}{ Age (years): } \\
\hline $5-9$ & 42.6 & 45.9 & 44.2 \\
\hline $10-14$ & 29.1 & 24.6 & 26.9 \\
\hline $15-19$ & 22.1 & 14.6 & 18.5 \\
\hline \multicolumn{4}{|l|}{ Residence: } \\
\hline North & 27.5 & 26.6 & 27.1 \\
\hline Centre & 30.8 & 22.1 & 26.5 \\
\hline Lisbon & 26.4 & 23.9 & 25.3 \\
\hline Alentejo & 25.1 & 20.4 & 22.9 \\
\hline Algarve & 30.4 & 23.8 & 27.4 \\
\hline Azores & 34.8 & 29.9 & 32.4 \\
\hline Madeira & 30.3 & 30.1 & 30.2 \\
\hline
\end{tabular}


Table 3 - Association between risk factors and child overweight/obesity

\begin{tabular}{|c|c|c|c|c|}
\hline Characteristics & Odds Ratio & \multicolumn{2}{|c|}{ 95\% $\mathrm{Cl}$ Odds Ratio } & $p$-value \\
\hline Male & 1.213 & 1.079 & 1.363 & 0.001 \\
\hline \multicolumn{5}{|l|}{ Age (years)*: } \\
\hline $5-9$ & 3.672 & 3.175 & 4.247 & 0.000 \\
\hline $10-14$ & 1.624 & 1.408 & 1.873 & 0.000 \\
\hline \multicolumn{5}{|l|}{ Residence ${ }^{\S}:$} \\
\hline North & 0.855 & 0.695 & 1.053 & 0.140 \\
\hline Centre & 0.866 & 0.694 & 1.080 & 0.201 \\
\hline Lisbon & 0.775 & 0,621 & 0,967 & 0.024 \\
\hline Alentejo & 0.689 & 0,544 & 0,872 & 0.002 \\
\hline Algarve & 0.861 & 0,691 & 1,073 & 0.183 \\
\hline Azores & 1.122 & 0,930 & 1,354 & 0.228 \\
\hline \multicolumn{5}{|l|}{ Income $(€)^{n}$ : } \\
\hline$\leq 150$ & 1.876 & 0.890 & 3.954 & 0.098 \\
\hline $151-250$ & 1.580 & 0.982 & 2.542 & 0.060 \\
\hline $251-350$ & 1.493 & 1.305 & 2.152 & 0.032 \\
\hline $351-500$ & 1.434 & 1.111 & 1.851 & 0.006 \\
\hline $501-700$ & 1.304 & 1.032 & 1.647 & 0.026 \\
\hline $701-900$ & 1.483 & 1.184 & 1.858 & 0.001 \\
\hline $901-1200$ & 1.307 & 1.046 & 1.633 & 0.019 \\
\hline $1201-1500$ & 1.159 & 0.911 & 1.474 & 0.230 \\
\hline $1501-2000$ & 1.207 & 0,916 & 1.591 & 0.182 \\
\hline \multicolumn{5}{|l|}{ Food intake: } \\
\hline Healthy food & 1.115 & 0.945 & 1.314 & 0.197 \\
\hline Unhealthy-sweets & 0.887 & 0.780 & 1.007 & 0.064 \\
\hline Unhealthy -drinks/chips & 1.373 & 1.193 & 1.586 & 0.000 \\
\hline
\end{tabular}


*The reference category is age $15-19 ;{ }^{\S}$ the reference category is Madeira; ${ }^{\text {"l }}$ the reference category is $>2000 €$. 


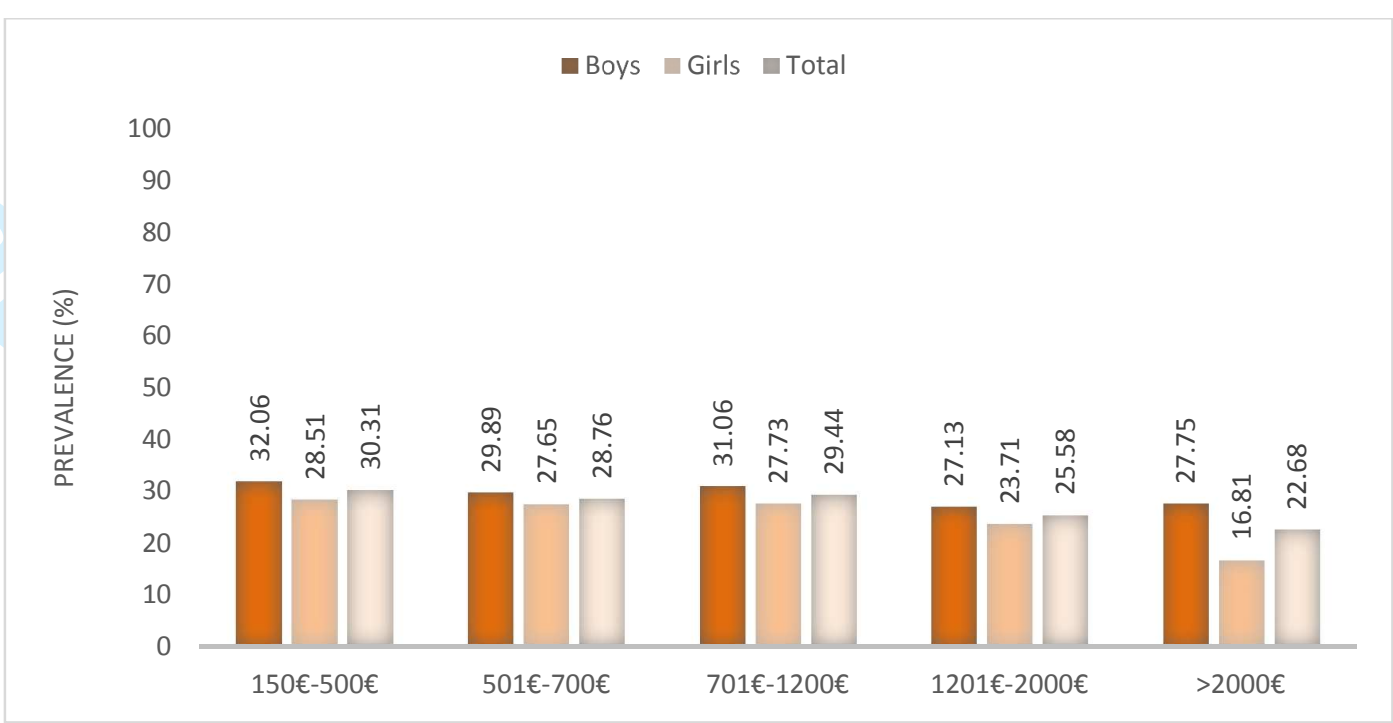

Figure 1. Prevalence of overweight/obesity by sex and monthly/family income in Portuguese children and adolescents aged 5 to 19, according to the International Obesity Task Force cut-offs of BMI 


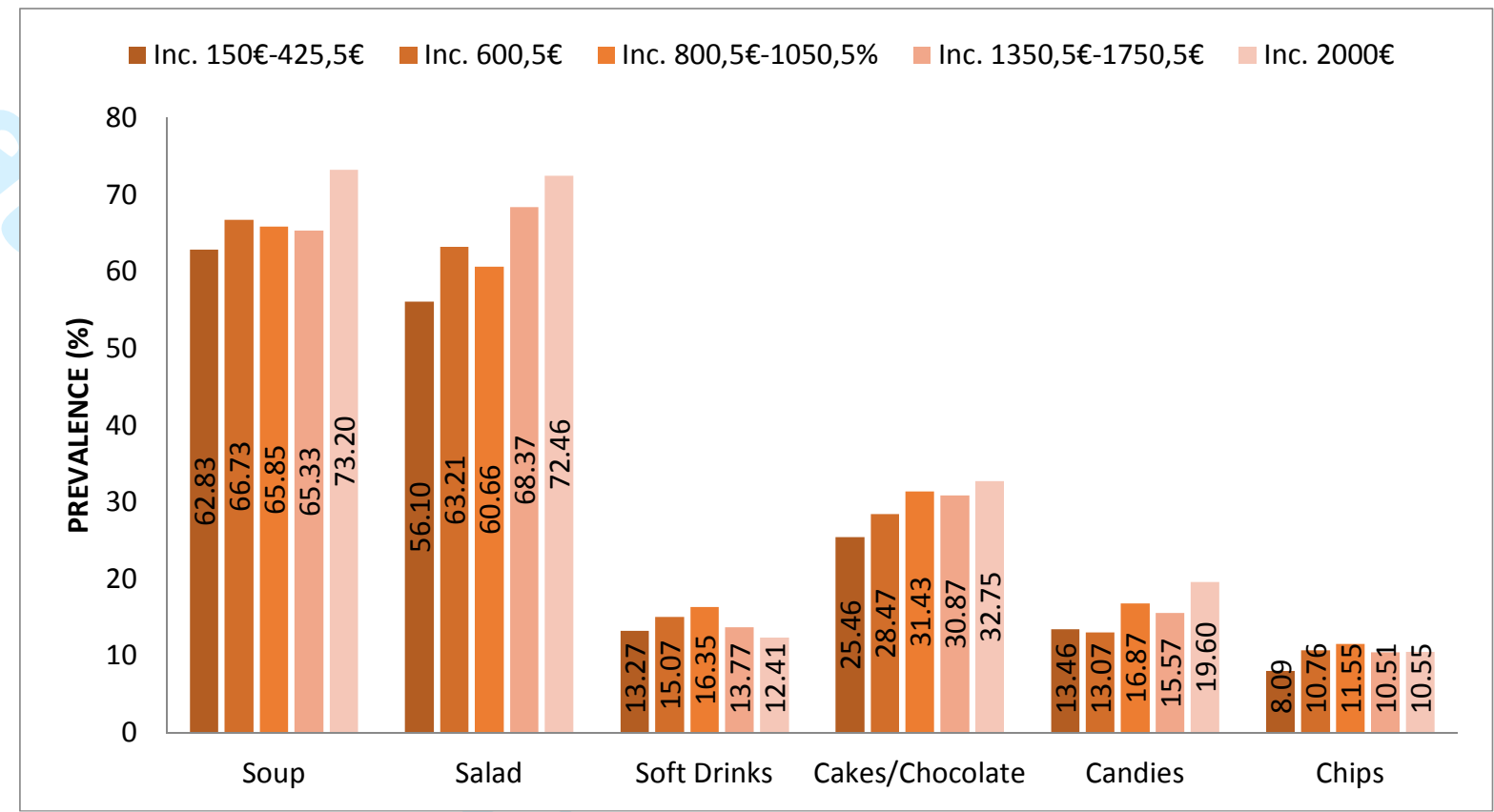

Figure 2. Dietary habits of Portuguese children and adolescents aged 5 to 19 years old by monthly/family income 


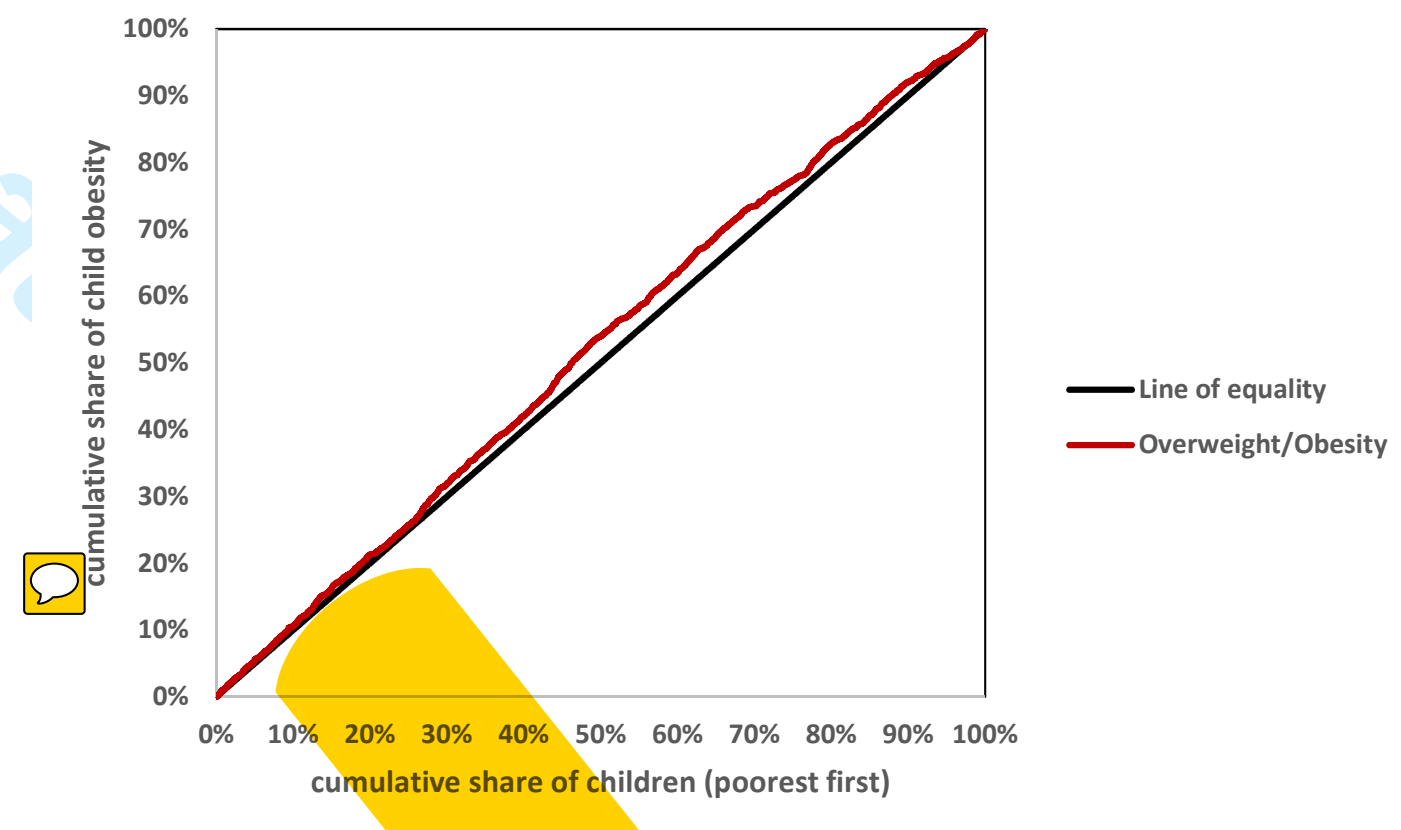

Figure 3. Concentration curve of overwight/obesity for Portuguese children and adolescents aged 5 to 19

Note: In the absence of inequality, the concentration curve coincides with the diagonal (line of equality); if the concentration curve lies above (below) the diagonal then the health variable (in this case, child overweight/obesity) is concentrated among the worse-off (better-off). 